\title{
Prognostic Role of Perihematomal Edema in Intracerebral Hemorrhage: A Systematic Review
}

\author{
Zhiyuan $\mathrm{YU}^{*}$, Lu MA*, Jun ZHENG*, Chao YOU \\ West China Hospital, Sichuan University, Department of Neurosurgery, Chengdu, China \\ *Zhiyuan YU, Lu MA and Jun ZHENG contributed equally to this work.
}

\section{ABSTRACT}

Although several studies have suggested perihematomal edema (PHE) is associated with prognosis in intracerebral hemorrhage $(\mathrm{ICH})$, the results are different in other studies. The purpose of this study was to evaluate the prognostic role of PHE in ICH. According to PRISMA guidelines, a systematic literature search of PubMed, EMBASE, SCOPUS, Web of Science and Cochrane Library was performed. Published clinical studies reporting association between PHE and prognosis in ICH were included. Data were extracted including sample size, patient characteristics, PHE measures, outcome measures and follow-up. A total of 21 studies were included with 6 prospective studies and 15 retrospective studies. PHE measures included perihematomal edema absolute volume (PHEAV), relative perihematomal edema volume (rPHE), perihematomal edema absolute volume growth (PHEAV growth), perihematomal edema expansion rate (PHEER), relative perihematomal edema growth (relative PHE growth), cytotoxic edema (CE) and perihematomal edema absolute area (PHEAA). The association of PHEAV/ rPHE /PHEAV growth and outcome are conflicting in different studies. Meta-analysis showed PHEER at 72 hours was significantly associated with poor clinical outcome at 90 days $(\mathrm{OR}=1.54,95 \% \mathrm{Cl} 1.04-2.22, \mathrm{p}<0.001)$. This study suggests the measures and time points for PHE and outcome are various in previous studies. The prognostic values of PHEAV, rPHE, PHEAV growth and other measures are still controversial. PHEER is likely a prognostic predictor for $\mathrm{ICH}$. Further studies with larger sample size, more accurate measures and more time points are needed to investigate the prognostic role of PHE in ICH and the optimal PHE measure to predict outcome in ICH.

KEYWORDS: Perihematomal edema, Intracerebral hemorrhage, Prognosis

\section{INTRODUCTION}

I ntracerebral hemorrhage $(\mathrm{ICH})$ is a severe type of stroke and accounts for about $10-15 \%$ of all strokes (43). Patients with ICH have high risk of severe disability or death (20). Cerebral injury secondary to $\mathrm{ICH}$ includes several complex mechanisms. Direct destruction and mass effect of hematoma bring primary injury to brain tissue at the beginning of $\mathrm{ICH}$ (13). Hematoma expansion further aggravates the primary injury (26). Inflammation, thrombin activation and erythrocyte lysis caused by primary injury lead to breakdown of brain blood barrier (BBB) and swelling of brain cells, which results in formation of perihematomal edema (PHE)(50). Thrombin formation induces BBB disruption and parenchymal cell death, which induces PHE formation in $\mathrm{ICH}$ (17). After erythrocyte lysis and hemoglobin release, AQP4 upregulation affected by the increased iron concentration has an important role in PHE (28). Complement activation rapidly induces downstream pathways of cerebral injury, which is correlated to formation of PHE (7). PHE can cause mass effect, which brings further cerebral injury (29). PHE is related to many factors, such as initial $\mathrm{ICH}$ volume, genetic variation, blood pressure, hyperglycemia and body temperature (42). PHE has been considered as an important target for treatment of $\mathrm{ICH}$ (16). New approaches aimed at PHE are hoped to improve prognosis of $\mathrm{ICH}$ patients $(5,9,33)$. Although many previous 
studies have suggested PHE may be associated with clinical outcome in $\mathrm{ICH}$, the PHE measures are various and the results are conflicting $(2,8,11,46,47)$. Thus, we conducted this systematic review to evaluate the prognostic role of PHE in $\mathrm{ICH}$.

\section{- MATERIAL and METHODS}

\section{Search Strategy}

A prespecified protocol following Preferred Reporting Items for Systematic Reviews and Meta-Analysis (PRISMA) Statement was followed. Two researchers (Zhiyuan YU \& Lu MA) independently searched literature in the PubMed (1958 to present), EMBASE (1980 to present), SCOPUS (1966 to present), Web of Science (1970 to present) and Cochrane Library on July 20,2016 . Our search strategy was combined by key words as following: "intracerebral hemorrhage" or "cerebral hemorrhage" or "intracerebral haemorrhage" or "cerebral haemorrhage" or "brain haemorrhage" or "brain haemorrhage" or "hemorrhagic stroke" or "haemorrhagic stroke" or "ICH" and "perihaematomal edema" or "perihaematomal oedema" or "perihematomal edema" or "perihematomal oedema" or "perihemorrhagic edema" or "perihaemorrhagic oedema" or "perihaemorrhagic edema" or "perihemorrhagic oedema" or "PHE" or "PHO" and "outcome" or "prognosis"or "predictor"or "mortality" or "death" or "disability" or "dependence" or "deterioration". MeSH terms were also adapted according to different indexing for each database. References of selected publications were also searched for potential literature. No language restrictions were set in our strategy.

\section{Study Selection}

The eligibility criteria for this systematic review were defined as following:

1. Published clinical studies in adult human beings

2. Sample size $\geq 20$ patients

3. ICH diagnosed by computed tomography (CT) or Magnetic Resonance Imaging (MRI)

4. Evaluating the association between PHE and prognosis in $\mathrm{ICH}$

5. Providing detailed method to evaluate PHE and prognosis

6. Providing credible data for PHE and prognosis.

Titles and abstracts of all included literature were screened by two reviewers independently. Full-text articles were obtained if studies were considered as potentially related to the association between PHE and prognosis by at least one reviewer. Full-text articles were screened by both reviewers for inclusion. If disagreement occurred, it would be resolved by the help of a third reviewer. Quality of study and risk of bias were evaluated by two reviewers (34).

\section{Data Extraction}

All relevant data were extracted by two reviewers independently with a standardized data abstraction form. All data were checked by the third reviewer for accuracy. Any pos- sible disagreement of data was solved by consensus of three reviewers. If different publications described the same group of patients, all publications were reviewed and the most representative one would be included. The following data were collected from each study: author, publication year, study design, sample size, study duration, inclusion/exclusion criteria, patient characteristics, PHE measures, outcome measures and follow-up.

\section{Statistical Analysis}

Because of the various measures for PHE and prognosis, we carefully considered if the meta-analysis was feasible. We decided if the meta-analysis was appropriate for each measure of PHE and prognosis by consensus. The evaluation of feasibility for meta-analysis was based on the methodology for meta-analysis of observational studies (10). If the metaanalysis was not appropriate to evaluate the association, we used the descriptive way to describe the results.

Our analyses focused on the association between PHE and outcome in ICH. All measures for PHE in included studies were analyzed. Only studies reporting odds ratios (OR) and 95\% confidence intervals (Cls) for the effect of a defined increment were included in meta-analysis (10). If adjusted ORs for confounding factors in multivariable analyses were available, we used the adjusted $\mathrm{OR}$ and $95 \% \mathrm{Cl}$ in the meta-analysis. Pooled ORs, $95 \% \mathrm{Cls}$, $\mathrm{p}$ values and Higgins $\mathrm{I}^{2}$ were calculated. If $I^{2}>50 \%$, we considered substantial heterogeneity existed between results of included studies. When no substantial heterogeneity existed, we used Woolf's method based on the fixed-effects model to calculate the pooled estimate; otherwise, we used the Der Simonian and Laird method based on the random-effects model (12). All statistical analysis was performed using STATA version 12.0 software (StataCorp., College Station, $T X)$. If $p<0.05$, it was considered as statistical significance.

\section{RESULTS}

A total of 21 studies between 1999 and 2016 were included from 805 original citations in 5 databases (Figure 1). Although data resource of Arima's and Yang's studies were both from INTERACT studies $(2,47)$, the measures for PHE were different, so both of them were included. In these 21 studies, 6 were prospective studies $(3,11,19,21,39,45)$, and 15 were retrospective studies $(1,2,8,18,23,27,30$ $32,35,36,40,46,47,52)$. Sample size ranged from 21 to 1310 patients. Sixteen studies assessed PHE with CT scan (1$3,8,11,18,21,23,27,30,31,35,40,46,47,52), 3$ studies used MRI $(19,39,45)$, and $2(32,36)$ studies had CT or MRI results to evaluate PHE (Table I).

Measures for PHE were various in 21 included studies. Perihematomal edema absolute volume (PHEAV) was accessed in 16 studies $(1,3,8,11,18,19,21,23,27,30-32,35,39,40,46)$, relative perihematomal edema volume (rPHE) was evaluated in 8 studies $(1,8,11,23,35,36,45,46), 7$ studies used perihematomal edema absolute volume growth (PHEAV growth) $(2,23,35,45$ 47,52), 2 studies adopted perihematomal edema expansion rate (PHEER) $(23,40)$, relative perihematomal edema growth 
Table I: Included Studies Evaluating Association Between PHE and Outcome in ICH

\begin{tabular}{lcccccc}
\hline Study & $\mathbf{n}$ & Study Design & Study Duration & $\begin{array}{c}\text { Neuro- } \\
\text { imaging }\end{array}$ & PHE Measures & Outcome Measures \\
\hline $\begin{array}{l}\text { Appelboom et al. } \\
\text { (2013) (1) }\end{array}$ & 133 & Retrospective Study & Feb. 2009-Jun. 2011 & CT & PHEAV \& rPHE & Functional Outcome \\
\hline $\begin{array}{l}\text { Arima et al. } \\
\text { (2009) (2) }\end{array}$ & 270 & Retrospective Study & $\begin{array}{c}\text { Nov. 2005- } \\
\text { Apr. 2007 }\end{array}$ & CT & $\begin{array}{c}\text { PHEAV Growth \& } \\
\text { relative PHE Growth }\end{array}$ & $\begin{array}{c}\text { Functional Outcome \& } \\
\text { Death }\end{array}$ \\
$\begin{array}{l}\text { Bakhshayesh } \\
\text { et al. (2014) (3) }\end{array}$ & 98 & Prospective Study & Jan. 2010-Jan. 2011 & CT & PHEAV & Death \\
$\begin{array}{l}\text { Gebel et al. } \\
\text { (2002) (8) }\end{array}$ & 103 & Retrospective Study & 1989-1994 & CT & PHEAV \& rPHE & Functional Outcome \\
$\begin{array}{l}\text { Gupta et al. } \\
\text { (2014) (11) }\end{array}$ & 44 & Prospective Study & Oct. 2010-Aug. 2012 & CT & PHEAV \& rPHE & Functional Outcome \\
$\begin{array}{l}\text { Levine et al. } \\
(2007)(18)\end{array}$ & 98 & Retrospective Study & Oct. 1998-Jun. 2004 & CT & PHEAV & Death
\end{tabular}

\begin{tabular}{|c|c|c|c|c|c|c|}
\hline Li et al. (2013) (19) & 21 & Prospective Study & Not Mentioned & MRI & PHEAV \& CE & Functional Outcome \\
\hline $\begin{array}{l}\text { McCarron et al. } \\
(1999)(21)\end{array}$ & 192 & Prospective Study & Not Mentioned & CT & PHEAV & Death \\
\hline $\begin{array}{l}\text { Murthy et al. } \\
(2016)(23)\end{array}$ & 596 & Retrospective Study & Not Mentioned & CT & $\begin{array}{c}\text { PHEAV \& rPHE \& } \\
\text { PHEAV Growth \& } \\
\text { PHEER }\end{array}$ & $\begin{array}{c}\text { Functional Outcome \& } \\
\text { Death }\end{array}$ \\
\hline $\begin{array}{l}\text { Ozdinc et al. } \\
(2016)(27) \\
\end{array}$ & 106 & Retrospective Study & Jan. 2012-Feb. 2015 & CT & PHEAV \& PHEAA & Death \\
\hline $\begin{array}{l}\text { Rodriguez-Luna et } \\
\text { al. (2016) (30) }\end{array}$ & 322 & Retrospective Study & Jun. 2006-Sep. 2010 & CT & PHEAV & $\begin{array}{c}\text { Functional Outcome } \\
\text { \& END }\end{array}$ \\
\hline $\begin{array}{l}\text { Sansing et al. } \\
(2003)(31)\end{array}$ & 80 & Retrospective Study & Jan. 1996-Dec. 1996 & CT & PHEAV & Discharge Disposition \\
\hline $\begin{array}{l}\text { Sansing et al. } \\
(2011)(32)\end{array}$ & 287 & Retrospective Study & Not Mentioned & $\begin{array}{l}\text { CT/ } \\
\text { MRI }\end{array}$ & PHEAV & Functional Outcome \\
\hline $\begin{array}{l}\text { Staykov et al. } \\
(2011)(35)\end{array}$ & 219 & Retrospective Study & Jan. 2006-Dec. 2009 & CT & $\begin{array}{l}\text { PHEAV\&rPHE\& } \\
\text { PHEAV Growth }\end{array}$ & Death \\
\hline $\begin{array}{l}\text { Sykora et al. } \\
(2009)(36)\end{array}$ & 38 & Retrospective Study & Oct. 2006-Dec. 2007 & $\begin{array}{l}\text { CT/ } \\
\text { MRI }\end{array}$ & rPHE & END \\
\hline $\begin{array}{l}\text { Tsai et al. } \\
(2011)(39) \\
\end{array}$ & 56 & Prospective Study & Not Mentioned & MRI & PHEAV \& CE & Functional Outcome \\
\hline $\begin{array}{l}\text { Urday et al. } \\
(2016)(40)\end{array}$ & 139 & Retrospective Study & $2000-2013$ & CT & PHEAV \& PHEER & $\begin{array}{c}\text { Functional Outcome \& } \\
\text { Death }\end{array}$ \\
\hline $\begin{array}{l}\text { Venkatasubramani- } \\
\text { an et al. (2011) (45) }\end{array}$ & 27 & Prospective Study & Not Mentioned & MRI & $\begin{array}{l}\text { rPHE \& PHEAV Growth } \\
\text { \& relative PHE Growth }\end{array}$ & $\begin{array}{l}\text { Functional Outcome \& } \\
\text { Death }\end{array}$ \\
\hline $\begin{array}{l}\text { Volbers et al. } \\
(2016)(46)\end{array}$ & 220 & Retrospective Study & Jan. 2006-Feb. 2010 & CT & $\begin{array}{l}\text { PHEAV \& rPHE \& } \\
\text { PHEAV Growth }\end{array}$ & Functional Outcome \\
\hline $\begin{array}{l}\text { Yang et al. } \\
(2015)(47) \\
\end{array}$ & 1310 & Retrospective Study & Nov. 2005-Aug. 2012 & CT & PHEAV Growth & $\begin{array}{c}\text { Functional Outcome \& } \\
\text { Death }\end{array}$ \\
\hline $\begin{array}{l}\text { Zubkov et al. } \\
(2008)(52)\end{array}$ & 88 & Retrospective Study & Jan. 1997-Dec. 2005 & CT & PHEAV Growth & $\begin{array}{c}\text { Functional Outcome \& } \\
\text { Death }\end{array}$ \\
\hline
\end{tabular}

PHE: Perihematomal edema, CT: Computed tomography, MRI: Magnetic resonance imaging, PHEAV: Perihematomal edema absolute volume, rPHE: Relative perihematomal edema volume, PHEAV growth: Perihematomal edema absolute volume growth, PHEER: Perihematomal edema expansion rate, relative PHE growth: Relative perihematomal edema growth, CE: Cytotoxic edema, PHEAA: Perihematomal edema absolute area, END: Early neurological deterioration. 


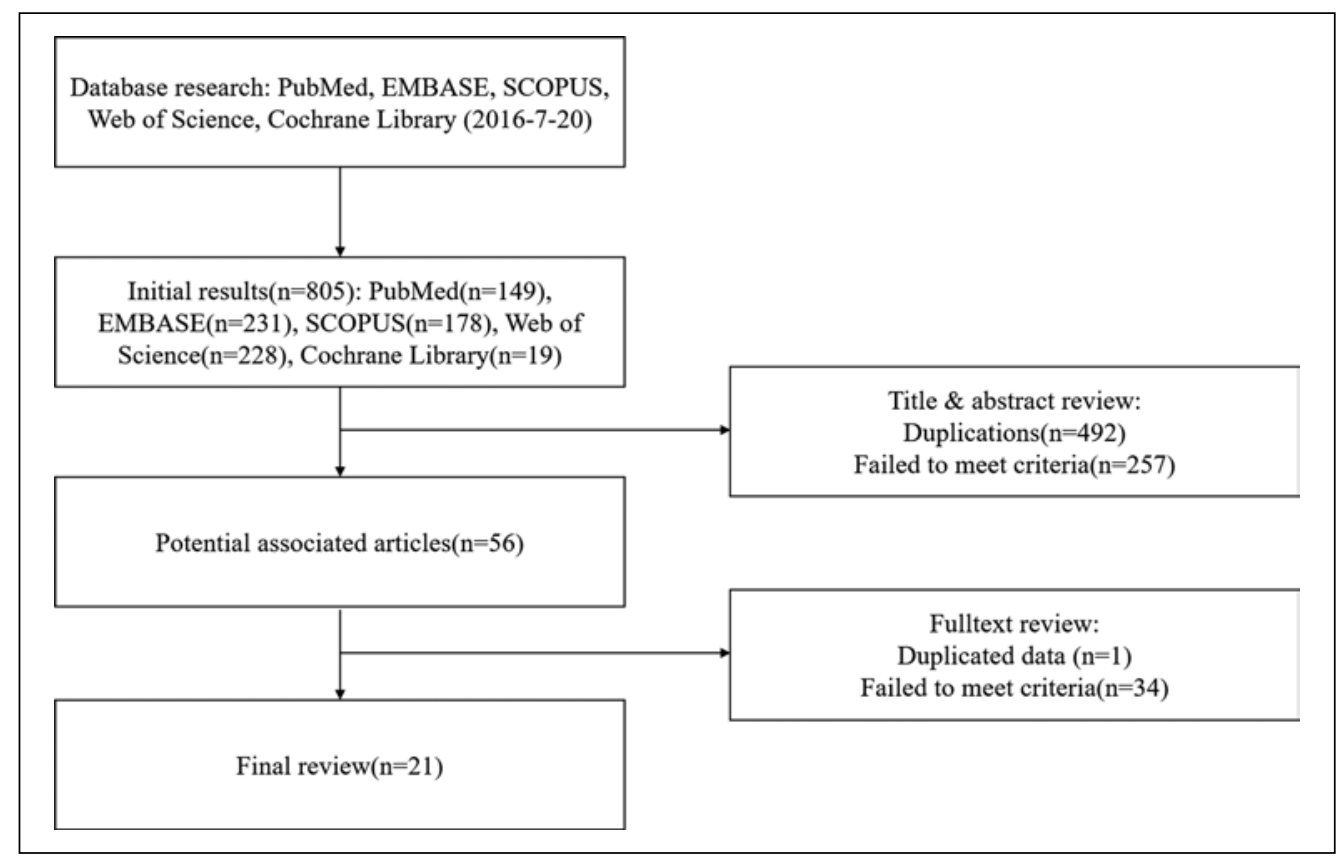

Figure 1: Study selection.

(relative PHE growth) was used in 2 studies $(2,45), 2$ studies accessed cytotoxic edema (CE) $(19,39)$, and perihematomal edema absolute area (PHEAA) was evaluated in 1 study (27). PHE measures had different time points in these studies (Table II).

In 21 included studies, 14 studies evaluated functional outcome $(1,2,8,11,19,23,30,32,39,40,45-47,52)$. Modified Rankin Scale (mRS) was used in all these 14 studies. Barther Index (BI) was adopted in 2 studies $(8,45)$. Death was accessed in 11 studies $(2,3,18,21,23,27,35,40,45,47,52)$. Early neurological deterioration (END) was evaluated in 2 studies $(30,36)$. Discharge disposition was used in 1 study $(31)$. There were also various time points for outcome assessment (Table III).

\section{PHEAV and Outcome in ICH}

A total of 8 studies discussed the association between baseline PHEAV and functional outcome in $\mathrm{ICH}(1,8,11,23,30,32,39,46)$. Because of insufficient studies with consistent outcome measure, a meta-analysis was not performed. In Appelboom's study, PHEAV was showed to be a significant predictor of short-term poor outcome $(\mathrm{mRS}>3)$ in $\mathrm{ICH}$ patients, especially in those with smaller $\mathrm{ICH}\left(\leq 30 \mathrm{~cm}^{3}\right)(1)$. Volbers et al. showed baseline PHEAV was significantly higher in those with poor outcome (mRS>3) at discharge (46). Rodriguez-Luna et al. found baseline PHEAV was higher in patients with a poor 90-day outcome (mRS $\geq 3$ ) (30). In Sansing's study, baseline PHEAV was found to be independently associated with worse clinical outcome (32). However, other 4 studies did not show a significant association between baseline PHEAV and functional outcome $(8,11,23,39)$.

The association between PHEAV at 72 hours $(72 h) / 3$ days(3d) and functional outcome was evaluated in 3 studies $(19,23,40)$.
Li's study showed 3d PHEAV was significantly larger in patients with unfavorable 90-day clinical outcome (mRS 4-6) (19). Murthy et al. found $72 \mathrm{~h}$ PHEAV was significantly associated with poor outcome (mRS3-6) at 90 days in multivariate analysis (23). In Urday's study, no significant association was found between $72 \mathrm{~h}$ PHEAV and poor functional outcome (mRS>2) at 90 days (40). Meta-analysis of Murthy's and Urday's studies showed a significant association between 72h PHEAV and poor functional outcome at 90 days $(\mathrm{OR}=1.02,95 \% \mathrm{Cl} 1.00$ 1.03, $p=0.007$ ) (Figure 2).

Six studies evaluated the association between baseline PHEAV and mortality in ICH $(3,18,21,23,27,35)$. Bakhshayesh's study suggested baseline PHEAV could predict the risk of inhospital mortality (3). McCarron et al. found non-survivors had larger edema volumes (21). In Staykov's study, initial PHEAV was found to be significantly associated with inhospital mortality (35). Ozdinc's study showed baseline PHEAV was significantly higher in non-survivors at 30 days (27). Baseline PHEAV was found to be a significant predictor for 90-day mortality in Warfarin-related ICH in Levine's study (18). However, Murthy's study showed baseline PHEAV was not significantly associated with mortality at 90 days (23). Meta-analysis of Levine's and Murthy's studies did not find a significant association between baseline PHEAV and mortality at 90 days $(\mathrm{OR}=0.71,95 \% \mathrm{Cl} 0.29-1.72, \mathrm{p}=0.446)$ (Figure 3$)$. The association between 72h PHEAV and 90-day mortality was assessed in 2 studies $(23,40)$. In Murthy's study, there was no significant association between 72h PHEAV and 90day mortality (23). Urday's study showed $72 \mathrm{~h}$ PHEAV was significantly associated with 90-day mortality in unadjusted analysis but insignificantly in adjusted analysis (40). Metaanalysis did not suggest significant association between $72 \mathrm{~h}$ PHEAV and 90-day mortality $(\mathrm{OR}=1.02,95 \% \mathrm{Cl}$ 0.99-1.04, $\mathrm{p}=0.180$ ) (Figure 4). 
Table II: Time Points of PHE Measures in 21 Included Studies

\begin{tabular}{|c|c|c|c|c|c|c|c|}
\hline Study & PHEAV & PHEAA & rPHE & $\begin{array}{l}\text { PHEAV } \\
\text { Growth }\end{array}$ & PHEER & $\begin{array}{l}\text { rPHE } \\
\text { Growth }\end{array}$ & CE \\
\hline Appelboom et al. (2013) (1) & Baseline & / & Baseline & / & / & / & / \\
\hline Arima et al. (2009) (2) & l & I & / & $72 \mathrm{~h}$ & / & $72 \mathrm{~h}$ & / \\
\hline Bakhshayesh et al. (2014) (3) & Baseline & / & / & / & / & / & / \\
\hline Gebel et al. (2002) (8) & Baseline & / & Baseline & / & / & / & / \\
\hline Gupta et al. (2014) (11) & Baseline & / & Baseline & / & / & / & / \\
\hline Levine et al. (2007) (18) & Baseline & / & / & / & / & / & / \\
\hline Li et al. (2013) (19) & $3 d$ & I & / & / & l & / & $3 d$ \\
\hline McCarron et al. (1999) (21) & Baseline & / & / & / & / & / & / \\
\hline Murthy et al. (2016) (23) & Baseline \& 72h & / & Baseline & $72 \mathrm{~h}$ & $72 \mathrm{~h}$ & / & / \\
\hline Ozdinc et al. (2016) (27) & Baseline & Baseline & / & / & / & / & / \\
\hline Rodriguez-Luna et al. (2016) (30) & Baseline & / & / & / & / & / & / \\
\hline Sansing et al. (2003) (31) & Baseline & / & / & / & / & / & / \\
\hline Sansing et al. (2011) (32) & Baseline & / & / & / & / & / & / \\
\hline Staykov et al. (2011) (35) & Baseline & / & $3 d$ & $3 d$ & / & / & / \\
\hline Sykora et al. (2009) (36) & / & / & $72 \mathrm{~h}$ & / & / & / & / \\
\hline Tsai et al. (2011) (39) & Baseline & / & / & / & / & / & Baseline \\
\hline Urday et al. (2016) (40) & $72 \mathrm{~h}$ & / & / & / & $24 \mathrm{~h} \& 72 \mathrm{~h}$ & / & / \\
\hline $\begin{array}{l}\text { Venkatasubramanian et al. } \\
(2011)(45)\end{array}$ & / & / & Peak & Peak & / & Peak & / \\
\hline Volbers et al. (2016) (46) & Baseline \& Peak & / & Peak & 48h\&Peak & / & / & / \\
\hline Yang et al. (2015) (47) & / & / & / & $24 \mathrm{~h}$ & / & / & / \\
\hline Zubkov et al. (2008) (52) & / & / & / & Peak & / & / & / \\
\hline
\end{tabular}

PHE: Perihematomal edema, PHEAV: Perihematomal edema absolute volume, rPHE: Relative perihematomal edema volume, PHEAV growth: perihematomal edema absolute volume growth, PHEER: Perihematomal edema expansion rate, relative PHE growth: Relative perihematomal edema growth, CE: Cytotoxic edema, PHEAA: Perihematomal edema absolute area.

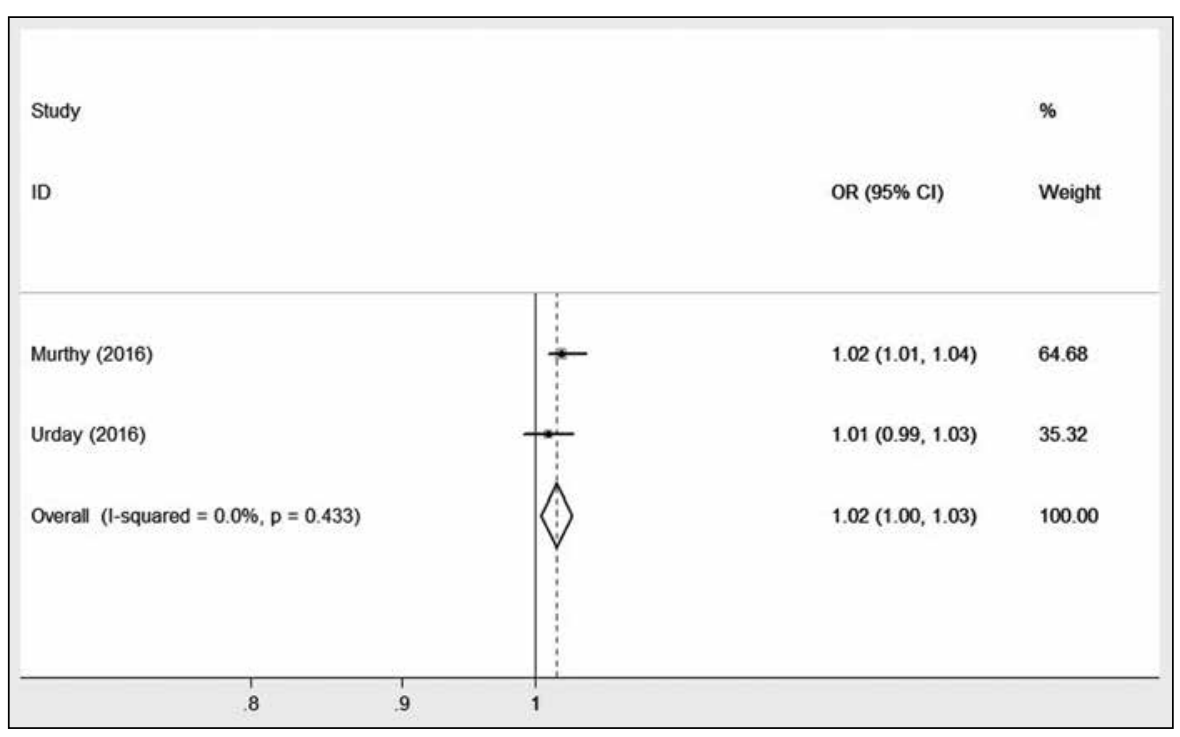

Figure 2: Meta-analysis of studies reporting an association between $72 \mathrm{~h}$ PHEAV and poor 90-day outcome. 
Table III: Outcome Measures in 21 Included Studies

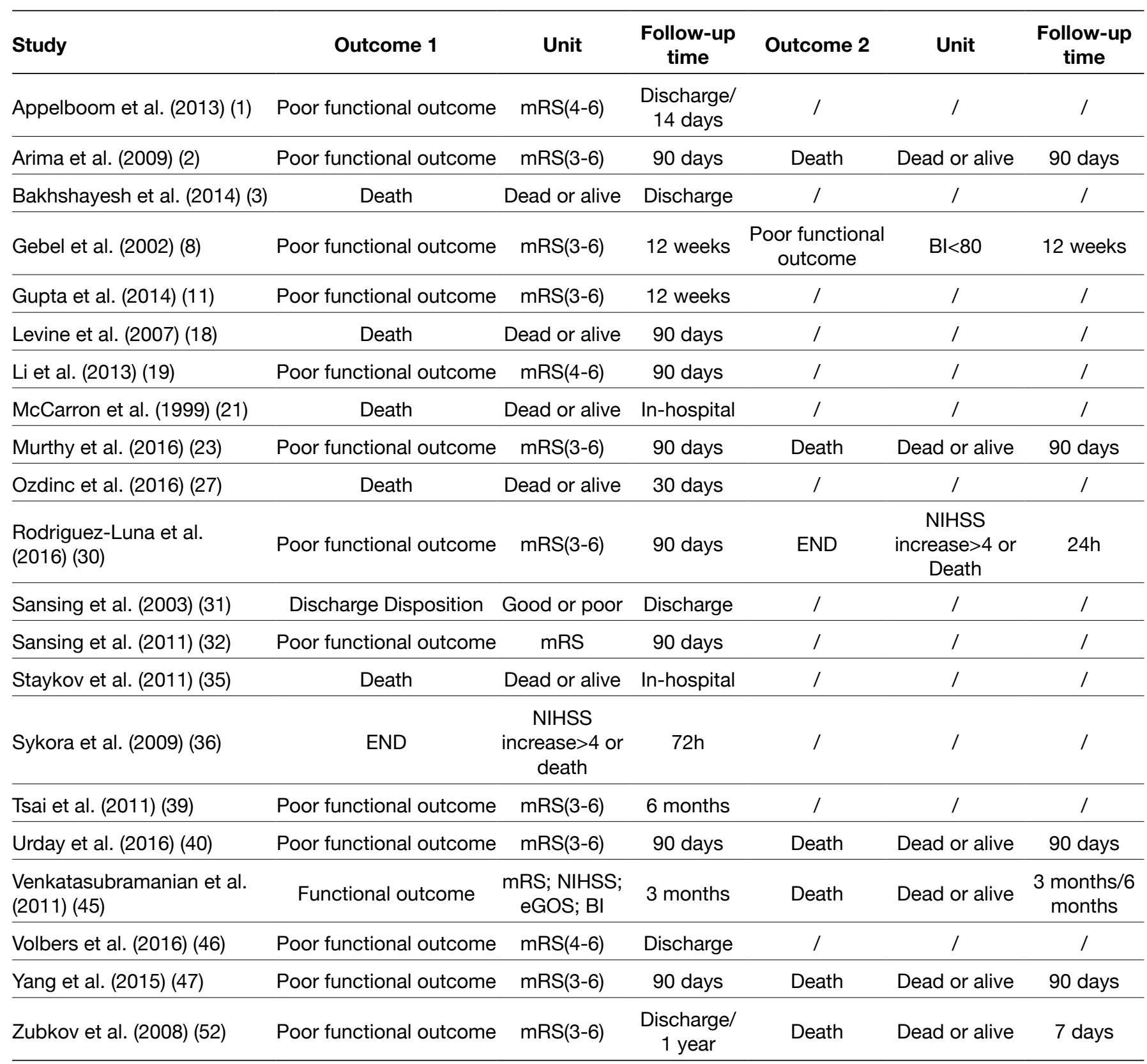

mRS: Modified Rankin scale, BI: Barther Index, NIHSS: National Institute of Health stroke scale, eGOS: Extended Glasgow outcome scale.

Rodriguez-Luna's study found baseline PHEAV was higher in patients with END (30). Sansing et al. suggested baseline PHEAV was correlated with poor discharge disposition (31).

\section{rPHE and Outcome in ICH}

Association between baseline rPHE and functional outcome was assessed in 4 studies $(1,8,11,23)$. Appelboom's study did not show a significant association between baseline rPHE and functional outcome at discharge (1). Increased baseline $\mathrm{rPHE}$ was found to be significantly associated with decreased probability of poor 12-week functional outcome (mRS>2) in Gebel's study (8). Gupta et al. suggested baseline rPHE was significantly associated with functional outcome $(\mathrm{MRS} \geq 3)$ at 3 months (11). However, no significant association between baseline rPHE and 90-day functional outcome (mRS3-6) was found in Murthy's study (23). Meta-analysis did not find a significant association between baseline rPHE and functional outcome at 90 days $/ 12$ weeks $(\mathrm{OR}=0.10,95 \% \mathrm{Cl} 0.01-1.91$, $p=0.127$ ) (Figure 5).

Two studies evaluated the association between peak rPHE and functional outcome and did not find significant association $(45,46)$. Volber's study did not show a significant association between $48 \mathrm{~h}$ rPHE and functional outcome (46). Associa- 

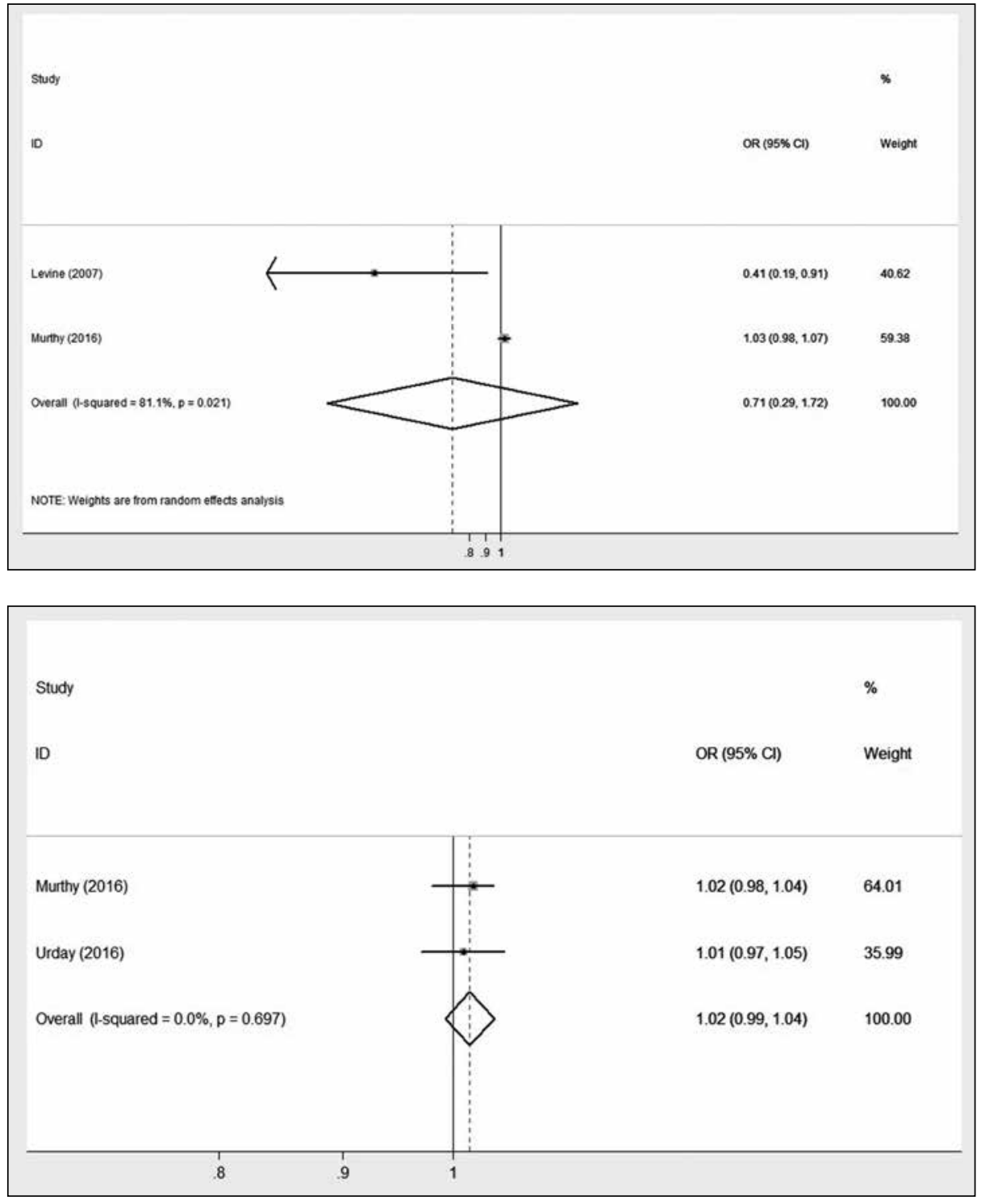

Figure 3: Meta-analysis of studies reporting an association between baseline PHEAV and 90-day mortality.

Figure 4: Meta-analysis of studies reporting an association between $72 \mathrm{~h}$ PHEAV and 90-day mortality.

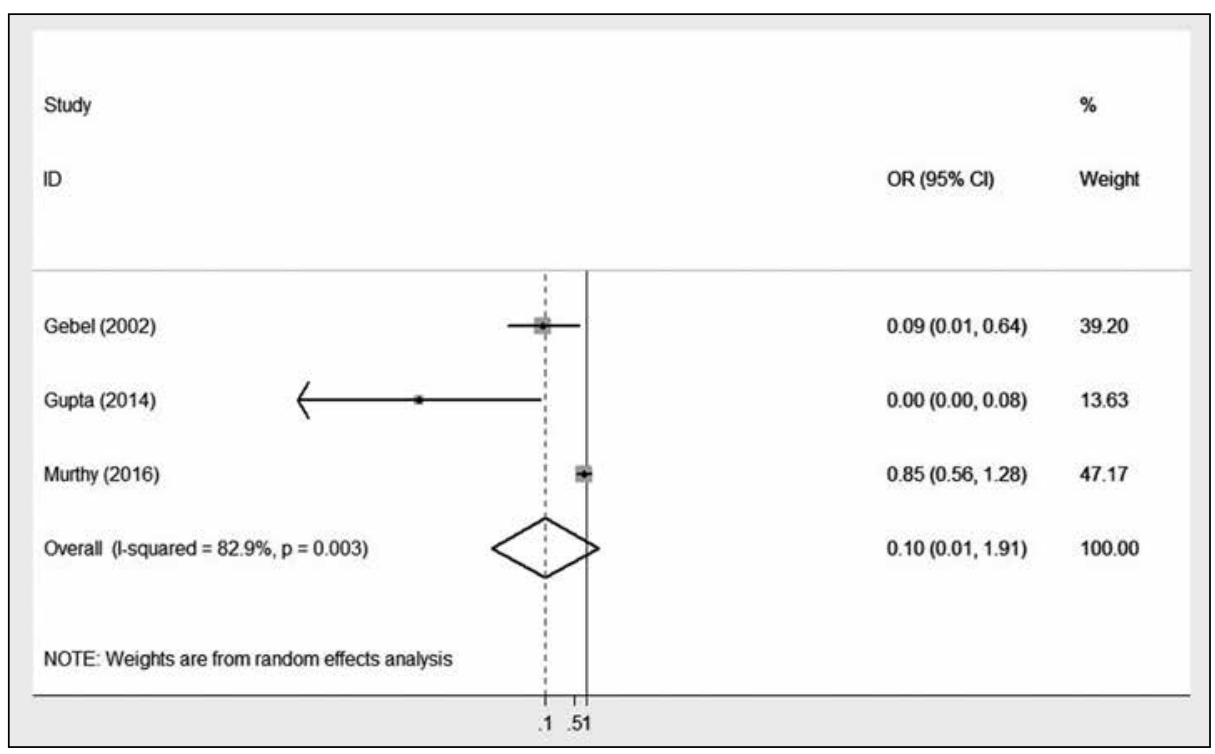

Figure 5: Meta-analysis of studies reporting an association between baseline rPHE and poor 90-day outcome. 
tion between rPHE and mortality was discussed in 3 studies $(23,35,45)$, and no significant association was identified. $72 \mathrm{~h}$ rPHE was found to be significantly associated with END in Sykora's study (36).

\section{PHEAV Growth and Outcome in ICH}

A total of 6 studies discussed the association between PHEAV growth and functional outcome in ICH $(2,23,45-47,52)$. Volbers et al. found higher PHEAV growth between day 1 and day 2-3 in patients with poor outcome at discharge (46). Yang's study suggested 24h PHEAV growth has significant association with poor outcome (mRS3-6)(47). No significant association between PHEAV growth and functional outcome was found in Venkatasubramanian's and Zubkov's studies $(45,52)$. Arima's study suggested $72 \mathrm{~h}$ PHEAV growth was associated with poor functional outcome significantly in univariate analysis, but insignificant after adjustment of age, sex, randomized treatment, and log of baseline hematoma volume (2). A significant association between $72 \mathrm{~h}$ PHEAV growth and poor functional outcome (mRS 3-6) at 90 days was found in Murthy's study (23). Meta-analysis of Arima's and Murthy's study did not show a significant association between $72 \mathrm{~h}$ PHEAV growth and 90-day poor functional outcome $(\mathrm{OR}=1.35$, $95 \% \mathrm{Cl}$ 0.81-2.26, $\mathrm{p}=0.255$ ) (Figure 6).

Association between PHEAV growth and mortality was assessed in 5 studies $(2,23,35,47,52)$. PHEAV growth between Day 1 and Day 3 was found to be associated with in-hospital mortality significantly in Staykov's study (35). Murthy's study showed a significant association between $72 \mathrm{~h}$ PHEAV growth and 90-day mortality (23). In Arima's study, 72h PHEAV growth was associated with 90-day mortality significantly in univariate analysis, but insignificantly after adjustment (2). No significant association between PHEAV growth and mortality was found in Yang's and Zubkov's studies $(47,52)$.

\section{PHEER and Outcome in ICH}

Association between PHEER and outcome in $\mathrm{ICH}$ was evaluated in 2 studies $(23,40)$. Urday's study suggested $24 \mathrm{~h}$ PHEER was significantly associated with worse mRS score and 72h PHEER was significantly associated with poor functional outcome (mRS 3-6) at 90 days (40). In Murthy's study, 72h PHEER was found to be significantly associated with poor functional outcome (mRS 3-6) and 90-day mortality (23). Meta-analysis showed the significant association between 72h PHEER and poor functional outcome (mRS 3-6) at 90 days $(\mathrm{OR}=1.62,95 \% \mathrm{Cl} 1.27-2.06, \mathrm{p}<0.001)$ (Figure 7).

\section{Other PHE Measures and Outcome in ICH}

Ozdinc's study showed perihematomal edema absolute area (PHEAA) was a simple value and an independent predictor for 30-day mortality (27). In Arima's study, $72 \mathrm{~h}$ relative PHE growth was associated with poor functional outcome at 90 days significantly in univariate analysis but insignificantly after adjustment, and $72 \mathrm{~h}$ relative PHE growth was not associated with 90-day mortality (2). No significant association was found between relative PHE growth (baseline to peak) and poor outcome at 3 months in Venkatasubramanian's study (45). Li's study suggested patients with CE at Day 3 tended to have poor outcome at 90 days (19). In Tsai's study, CE was found to be significantly associated with poor clinical outcome at 6 months (39).

\section{DISCUSSION}

Most ICH patients have PHE during the course of the disease, which increases the mass effect (38). Early PHE starts after ictus of $\mathrm{ICH}$ and peaks at 4-5 days, which is mainly caused by vasogenic effect of pro-osmotic substances from the hematoma; delayed PHE lasts for about 2-4 weeks, which is affected by both vasogenic and cytotoxic effects (4). PHE increases significantly during first 24 hours after ictus of $\mathrm{ICH}$ (37). PHE is influenced by many factors, such as hematoma volume, hematoma expansion, intraventricular hemorrhage, hypertension and diabetes (15). Hematoma volume is correlative to PHE (22). It is reported that the association between hematoma volume and PHE increases in large hematomas and decreases in small hematomas over time $(44,48,51)$. Ambient temperature has association with PHE volume in acute spontaneous ICH (49). PHE development in $\mathrm{ICH}$ is higher in diabetic patients (14). It is reported that statin use prior to $\mathrm{ICH}$ is related to decreased PHE (24). As more and more studies suggest PHE may be associated with outcome in $\mathrm{ICH}$, new methods are developed to reduce PHE $(16,48)$. However, although several studies suggest PHE is a prognostic factor for $\mathrm{ICH}$, some other studies have different results. Moreover, different studies have different measures for PHE and the best measure for PHE is still uncertain. We performed this systematic review and meta-analysis to evaluate the prognostic value of different measures for PHE. Finally, a total of 21 studies were included in this systematic review and meta-analysis.

Most of the studies (16/21, 76.19\%) evaluated PHE with CT scan. It is more difficult to measure PHE with CT scan because the boundaries of PHE become unclear during the course of ICH (45). It is also challenging to distinguish PHE from normal tissue and infarction which presents as perihematomal hypodensity (6). An approach based on a quantitative edgedetection algorithm was developed to improve the accuracy of PHE measurement based on CT scan (41). MRI is another neuroimaging method to determine PHE after $\mathrm{ICH}$. Three (14.29\%) studies determined PHE with MRI and 2 (9.52\%) studies assessed PHE with results of CT or MRI. MRI can suggest significant perfusion delay and facilitated diffusion admixed with restricted diffusion in the region of PHE (25). ADC can suggest the existence of cytotoxic and vasogenic edema (39). Further studies should measure PHE accurately with both $\mathrm{CT}$ and MRI.

PHEAV is the most frequent measure for PHE (16/21, $76.19 \%)$. The time points in these studies are different and baseline PHEAV is assessed most frequently (14/16, 87.50\%). Although 4 studies showed baseline PHEAV was significantly associated with functional outcome $(1,30,32,46)$, other 4 studies did not have the same results $(8,11,23,39)$. In 3 studies evaluating association between 72h PHEAV and functional outcome $(19,23,40), 2$ studies showed $72 \mathrm{~h}$ PHEAV was significantly associated with functional outcome $(19,23)$, 

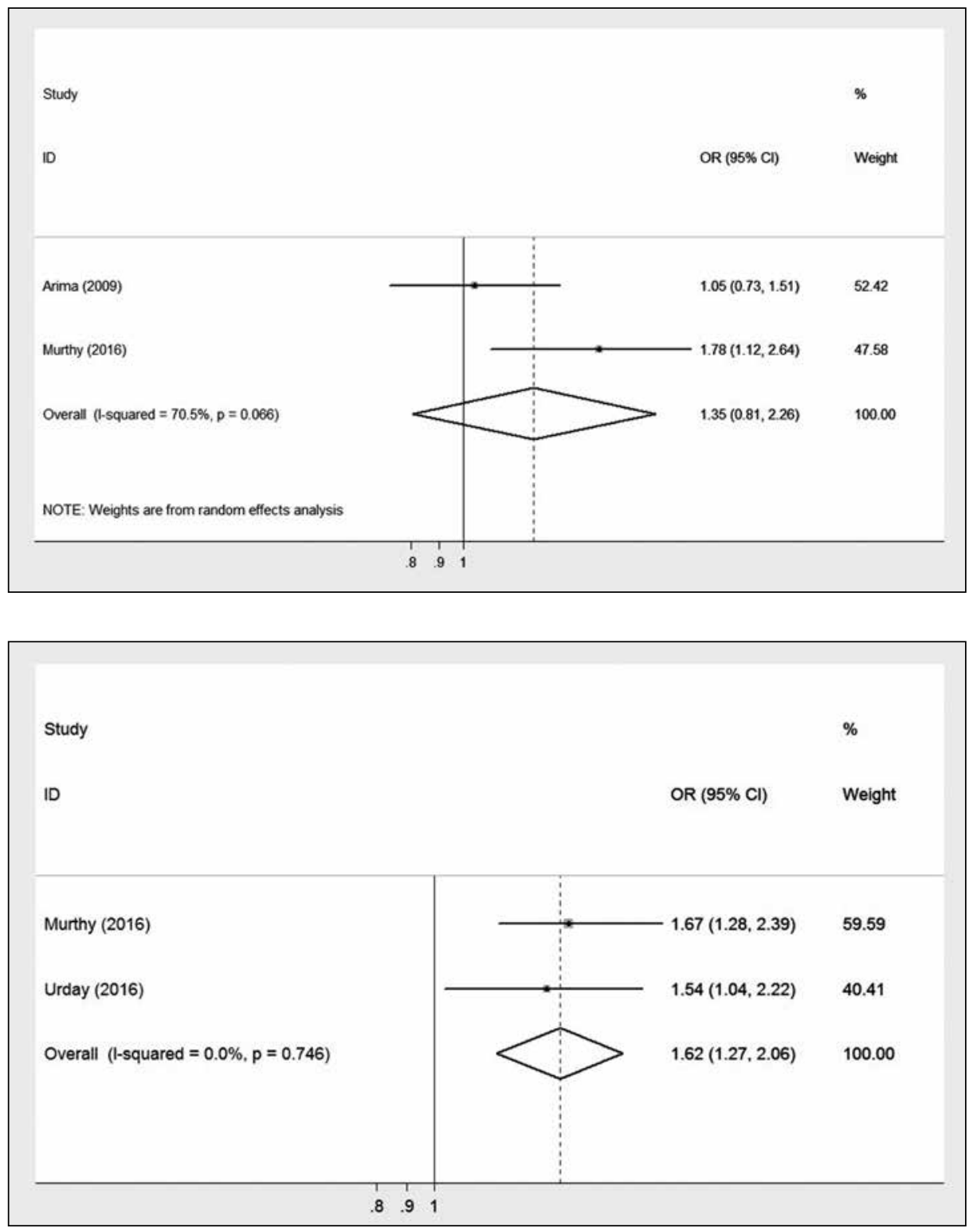

Figure 6: Meta-analysis of studies reporting an association between 72h PHEAV growth and poor 90-day outcome.
Figure 7: Meta-analysis of studies reporting an association between $72 \mathrm{~h}$ PHEER and poor 90-day outcome. while another study did not (40). Meta-analysis of Murthy's and Urday's studies $(23,40)$ found a significant association between $72 \mathrm{~h}$ PHEAV and functional outcome at 90 days. In 6 studies assessing the association between baseline PHEAV and mortality in $\mathrm{ICH}, 5$ studies find the baseline PHEAV was significantly associated with mortality $(3,18,21,27,35)$, but Murthy's study (23), and meta-analysis of Levine's and Murthy's studies $(18,23)$ did not show the significant association. In 2 studies evaluating association between 72h PHEAV and 90day mortality, both results of 2 studies and meta-analysis suggest no significant association. It seems that PHEAV may have prognostic value for $\mathrm{ICH}$ patients PHEAV. However, the exact association needs more studies to confirm.

rPHE is defined as PHEAV divided by hematoma volume (8). A total of $8(38.10 \%)$ studies evaluate the prognostic role of $r \mathrm{PHE}$ in $\mathrm{ICH}$. In 4 studies discussing association between baseline rPHE and functional outcome $(1,8,11,23), 2$ studies suggest significant association $(8,11)$, while other 2 studies $(1,23)$, and meta-analysis of 3 studies did not $(8,11,23)$. No significant association between Peak/48h rPHE and functional outcome was found $(45,46)$. No significant association between $\mathrm{rPHE}$ and mortality was showed $(23,35,45)$. One study showed $72 \mathrm{~h}$ rPHE was significantly associated with END (36). Further studies are needed to determine the association between $\mathrm{rPHE}$ and outcome in $\mathrm{ICH}$.

In all 6 studies evaluating association between PHEAV growth and functional outcome $(2,23,45-47,52), 3$ studies suggested significant association $(23,46,47), 2$ studies showed no significant association (45,52), and 1 study (2) had different results before and after adjustment. Meta-analysis of 2 studies did not show significant association between $72 \mathrm{~h}$ PHEAV growth $(2,23)$, and 90-day poor functional outcome. 5 studies assessing the association between PHEAV growth and mortality in $\mathrm{ICH}(2,23,35,47,52)$. A significant association 
was found in 2 studies $(23,35)$, while 2 studies $(47,52)$ did not show a significant association. Different results were showed before and after adjustment in 1 study (2). The prognostic value of PHEAV growth in $\mathrm{ICH}$ is still uncertain.

PHEER is defined as (PHE at time point-PHE at baseline)/ (time to time point CT scan-time to baseline CT scan, hours) and unit is $\mathrm{mL} /$ hour (23). The prognostic value of PHEER in $\mathrm{ICH}$ was discussed in 2 studies. 24h PHEER was found to be associated with significantly worse mRS $(40)$. The results of 2 studies $(23,40)$, and meta-analysis suggested significant association between $72 \mathrm{~h}$ PHEER and poor functional outcome at 90 days. $72 \mathrm{~h}$ PHEER was also found to be associated with 90-day mortality significantly (23). PHEER seems to be an important predictor for outcome in $\mathrm{ICH}$. Further studies are necessary to prove the prognostic role of PHEER in ICH.

Some other measures for PHE were also evaluated in included studies. PHEAA seems to be a predictor for outcome in $\mathrm{ICH}$ (27), but more studies are needed to confirm. Relative PHE growth was not found to be associated with the outcome in ICH $(2,45)$. CE determined by MRI was found to be potential prognostic factor in $\mathrm{ICH}(19,39)$, but its prognostic value should be examined in more studies.

During the first 24 hours, PHE increases greatly (40). The rapid growth of PHE remains during next 48 hours and PHE has its peak volume at the average of 12 days (45). PHE has mass effects leading high intracranial pressure and even herniation, which may influence the clinical outcome in $\mathrm{ICH}$ (46). Moreover, the factors involved in PHE development represent several devastating processes for brain, such as thrombin formation, erythrocyte lysis, hemoglobin toxicity and complement activation (50). Thus, PHE is considered to be associated with outcome, but the best measure for PHE to predict prognosis in $\mathrm{ICH}$ is still unclear (42). Some studies suggest PHEAV, rPHE and PHEAV growth are associated with outcome $(1,8,47)$, and PHEER seems to be an important predictor for outcome in ICH patients $(23,40)$. However, due to the complicated mechanism and process of PHE, further studies need more accurate PHE measures with more time points to investigate the prognostic value of PHE and the best PHE measure to predict outcome in $\mathrm{ICH}$.

This systematic review has several limitations. First, different measures and time points for PHE and outcome were adapted in included studies, only studies with same measure, same time point and adjusted ORs were included in metaanalysis. Thus, the statistical power of meta-analysis was limited. Moreover, the meta-analysis was performed based on adjusted ORs instead of original data. Furthermore, the factors for adjustment in different studies were various, which brought confounders to the results.

\section{- CONCLUSION}

This systematic review suggests that current evidence about prognostic role of PHE in ICH has high heterogeneity. The measures and time points for PHE and outcome are various. The prognostic values of PHEAV, rPHE, PHEAV growth and other measures are still controversial. PHEER seems to be a prognostic predictor for $\mathrm{ICH}$. Further studies with larger sample size, more accurate measures and more time points are needed to investigate the prognostic role of PHE in $\mathrm{ICH}$ and the best PHE measure to predict outcome in $\mathrm{ICH}$.

\section{REFERENCES}

1. Appelboom G, Bruce SS, Hickman ZL, Zacharia BE, Carpenter AM, Vaughan KA, Duren A, Hwang RY, Piazza M, Lee K, Claassen J, Mayer S, Badjatia N, Connolly ES Jr: Volumedependent effect of perihaematomal oedema on outcome for spontaneous intracerebral haemorrhages. J Neurol Neurosurg Psychiatry 84(5): 488-493, 2013

2. Arima $H$, Wang JG, Huang $Y$, Heeley E, Skulina C, Parsons MW, Peng B, Li Q, Su S, Tao QL, Li YC, Jiang JD, Tai LW, Zhang JL, Xu E, Cheng Y, Morgenstern LB, Chalmers J, Anderson CS; INTERACT Investigators: Significance of perihematomal edema in acute intracerebral hemorrhage: The INTERACT trial. Neurology 73(23):1963-1968, 2009

3. Bakhshayesh B, Hosseininezhad M, Saadat SMS, Hajmanuchehri M, Kazemnezhad E, Ghayeghran AR: Predicting in-hospital mortality in Iranian patients with spontaneous intracerebral hemorrhage. Iranian J Neurol 13(4): 231-236, 2014

4. Balami JS, Buchan AM: Complications of intracerebral haemorrhage. Lancet Neurol 11(1): 101-118, 2012

5. Barnes B, Hanley DF, Carhuapoma JR: Minimally invasive surgery for intracerebral haemorrhage. Curr Opin Crit Care 20(2): 148-152, 2014

6. Carhuapoma JR, Hanley DF, Banerjee M, Beauchamp NJ: Brain edema after human cerebral hemorrhage: A magnetic resonance imaging volumetric analysis. J Neurosurg Anesthesiol 15(3): 230-233, 2003

7. Ducruet AF, Zacharia BE, Hickman ZL, Grobelny BT, Yeh ML, Sosunov SA, Connolly ES Jr: The complement cascade as a therapeutic target in intracerebral hemorrhage. Exp Neurol 219(2): 398-403, 2009

8. Gebel JM Jr, Jauch EC, Brott TG, Khoury J, Sauerbeck L, Salisbury S, Spilker J, Tomsick TA, Duldner J, Broderick JP: Relative edema volume is a predictor of outcome in patients with hyperacute spontaneous intracerebral hemorrhage. Stroke 33(11): 2636-2641, 2002

9. Gomes JA, Manno E: New developments in the treatment of intracerebral hemorrhage. Neurol Clin 31(3): 721-735, 2013

10. Greenland S: Quantitative methods in the review of epidemiologic literature. Epidemiol Rev 9: 1-30, 1987

11. Gupta M, Verma R, Parihar A, Garg RK, Singh MK, Malhotra HS: Perihematomal edema as predictor of outcome in spontaneous intracerebral hemorrhage. J Neurosci Rural Pract 5(1): 48-54, 2014

12. Higgins JP, Thompson SG: Quantifying heterogeneity in a meta-analysis. Stat Med 21(11): 1539-1558, 2002

13. Keep RF, Hua Y, Xi G: Intracerebral haemorrhage: Mechanisms of injury and therapeutic targets. Lancet Neurol 11(8): 720731,2012

14. Kemal B, Talip A, Nermin T, Yahya C, Ufuk U: Volume of perihematomal edema in diabetic patients. Turk Serebrovaskuler Hastaliklar Dergisi 12(3): 73-76, 2006 
15. Kim H, Edwards NJ, Choi HA, Chang TR, Jo KW, Lee K: Treatment strategies to attenuate perihematomal edema in patients with intracerebral hemorrhage. World Neurosurg 94:32-41, 2016

16. Leasure A, Kimberly WT, Sansing LH, Kahle KT, Kronenberg G, Kunte H, Simard JM, Sheth KN: Treatment of edema associated with intracerebral hemorrhage. Curr Treat Options Neurol 18(2): 9, 2016

17. Lee KR, Kawai N, Kim S, Sagher O, Hoff JT: Mechanisms of edema formation after intracerebral hemorrhage: Effects of thrombin on cerebral blood flow, blood-brain barrier permeability, and cell survival in a rat model. J Neurosurg 86(2): 272-278, 1997

18. Levine JM, Snider R, Finkelstein D, Gurol ME, Chanderraj R, Smith EE, Greenberg SM, Rosand J: Early edema in warfarinrelated intracerebral hemorrhage. Neurocrit Care 7(1):58-63, 2007

19. Li N, Worthmann H, Heeren M, Schuppner R, Deb M, Tryc $A B$, Bueltmann $E$, Lanfermann $H$, Donnerstag $F$, Weissenborn $\mathrm{K}$, Raab P: Temporal pattern of cytotoxic edema in the perihematomal region after intracerebral hemorrhage: A serial magnetic resonance imaging study. Stroke 44(4):1144-1146, 2013

20. Löppönen P, Qian C, Tetri S, Juvela S, Huhtakangas J, Bode MK, Hillbom M: Predictive value of C-reactive protein for the outcome after primary intracerebral hemorrhage. J Neurosurg 121(6): 1374-1379, 2014

21. McCarron MO, Hoffmann KL, DeLong DM, Gray L, Saunders AM, Alberts MJ: Intracerebral hemorrhage outcome: Apolipoprotein $\mathrm{E}$ genotype, hematoma, and edema volumes. Neurology 53(9): 2176-2179, 1999

22. Murthy S, Moradiya Y, Dawson J, Lees K, Hanley D, Ziai W, VISTA-ICH Collaborators: Perihematomal edema and functional outcomes in intracerebral hemorrhage: Influence of hematoma volume and location. Stroke 46(11): 3088-3092, 2015

23. Murthy SB, Urday S, Beslow LA, Dawson J, Lees K, Kimberly WT, ladecola C, Kamel H, Hanley DF, Sheth KN, Ziai WC, Butcher K, Davis S, Gregson B, Lyden KLP, Mayer S, Muir $\mathrm{K}$, Steiner $\mathrm{T}$ : Rate of perihaematomal oedema expansion is associated with poor clinical outcomes in intracerebral haemorrhage. J Neurol Neurosurg Psychiatry 87(11):11691173, 2016

24. Naval NS, Abdelhak TA, Urrunaga N, Zeballos P, Mirski MA, Carhuapoma JR: An association of prior statin use with decreased perihematomal edema. Neurocrit Care 8(1):13-18, 2008

25. Olivot JM, Mlynash M, Kleinman JT, Straka M, Venkatasubramanian C, Bammer R, Moseley ME, Albers GW, Wijman CA: MRI profile of the perihematomal region in acute intracerebral hemorrhage. Stroke 41(11): 2681-2683, 2010

26. Orito K, Hirohata M, Nakamura Y, Takeshige N, Aoki T, Hattori G, Sakata K, Abe T, Uchiyama Y, Sakamoto T, Morioka M: Leakage sign for primary intracerebral hemorrhage: A novel predictor of hematoma growth. Stroke 47(4): 958-963, 2016
27. Ozdinc S, Unlu E, Karakaya Z, Turamanlar O, Dogan N, Isler Y, Gonul Y, Boyaci MG: Prognostic value of perihematomal edema area at the initial ED presentation in patients with intracranial hematoma. Am J Emerg Med 34(7):1241-1246, 2016

28. Qing WG, Dong YQ, Ping TQ, Lai LG, Fang LD, Min HW, Xia L, Heng PY: Brain edema after intracerebral hemorrhage in rats: The role of iron overload and aquaporin 4. J Neurosurg 110(3): 462-468, 2009

29. Qureshi Al, Palesch YY, Martin R, Novitzke J, Cruz-Flores S, Ehtisham A, Ezzeddine MA, Goldstein JN, Hussein HM, Suri FK, Tariq N: Effect of systolic blood pressure reduction on hematoma expansion, perihematomal edema, and 3-month outcome among patients with intracerebral hemorrhage: Results from the antihypertensive treatment of acute cerebral hemorrhage study. Arch Neurol 67(5): 570-576, 2010

30. Rodriguez-Luna D, Stewart T, Dowlatshahi D, Kosior JC, Aviv RI, Molina CA, Silva Y, Dzialowski I, Lum C, Czlonkowska A, Boulanger JM, Kase CS, Gubitz G, Bhatia R, Padma V, Roy J, Subramaniam S, Hill MD, Demchuk AM, Study PSIC: Perihematomal edema is greater in the presence of a spot sign but does not predict intracerebral hematoma expansion. Stroke 47(2): 350-355, 2016

31. Sansing LH, Kaznatcheeva EA, Perkins CJ, Komaroff E, Gutman FB, Newman GC: Edema after intracerebral hemorrhage: Correlations with coagulation parameters and treatment. J Neurosurg 98(5): 985-992, 2003

32. Sansing LH, Messe SR, Cucchiara BL, Lyden PD, Kasner SE: Anti-adrenergic medications and edema development after intracerebral hemorrhage. Neurocrit Care 14(3): 395-400, 2011

33. Sonni S, Lioutas VA, Selim MH: New avenues for treatment of intracranial hemorrhage. Curr Treat Options Cardiovasc Med 16(1): 277, 2014

34. Stang A: Critical evaluation of the Newcastle-Ottawa scale for the assessment of the quality of nonrandomized studies in meta-analyses. Eur J Epidemiol 25(9): 603-605, 2010

35. Staykov D, Wagner I, Volbers B, Hauer EM, Doerfler A, Schwab S, Bardutzky J: Natural course of perihemorrhagic edema after intracerebral hemorrhage. Stroke 42(9): 26252629, 2011

36. Sykora M, Diedler J, Turcani P, Rupp A, Steiner T: Subacute perihematomal edema in intracerebral hemorrhage is associated with impaired blood pressure regulation. J Neurol Sci 284 (1-2): 108-112, 2009

37. Tohidi V, Mughni A, Ahmad H, Hassanzadeh B, El-Gengaihy $A E$, Kirmani J: Correlation of perihematoma edema in patients with spontaneous intracerebral hemorrhage with clinical outcomes using novel technique of 3D volumetric measurement. Stroke 40(4): e231, 2009

38. Towfighi A, Greenberg SM, Rosand J: Treatment and prevention of primary intracerebral hemorrhage. Semin Neurol 25(4): 445-452, 2005

39. Tsai $\mathrm{YH}$, Hsu LM, Weng $\mathrm{HH}$, Lee MH, Yang JT, Lin CP: Voxel-based analysis of apparent diffusion coefficient in perihaematomal oedema: Associated factors and outcome predictive value for intracerebral haemorrhage. BMJ Open 1(1): e000230, 2011 
40. Urday S, Beslow LA, Dai F, Zhang F, Battey TW, Vashkevich A, Ayres AM, Leasure AC, Selim MH, Simard JM, Rosand J, Kimberly WT, Sheth KN: Rate of perihematomal edema expansion predicts outcome after intracerebral hemorrhage. Crit Care Med 44(4): 790-797, 2016

41. Urday S, Beslow LA, Goldstein DW, Vashkevich A, Ayres AM, Battey TW, Selim MH, Kimberly WT, Rosand J, Sheth $\mathrm{KN}$ : Measurement of perihematomal edema in intracerebral hemorrhage. Stroke 46(4): 1116-1119, 2015

42. Urday S, Kimberly WT, Beslow LA, Vortmeyer AO, Selim MH, Rosand J, Simard JM, Sheth KN: Targeting secondary injury in intracerebral haemorrhage-perihaematomal oedema. Nat Rev Neurol 11(2): 111-122, 2015

43. van Asch CJ, Luitse MJ, Rinkel GJ, van der Tweel I, Algra A, Klijn CJ: Incidence, case fatality, and functional outcome of intracerebral haemorrhage over time, according to age, sex, and ethnic origin: A systematic review and meta-analysis. Lancet Neurol 9(2):167-176, 2010

44. Venkatasubramanian C, Aksoy D, Narayana R, Mlynash M, Eyngorn I, Snider R, Wijman C: A comparison of the evolution of perihematomal edema volume between large and small intraparenchymal hematomas. Neurocrit Care 13: S106, 2010

45. Venkatasubramanian C, Mlynash M, Finley-Caulfield A, Eyngorn I, Kalimuthu R, Snider RW, Wijman CA: Natural history of perihematomal edema after intracerebral hemorrhage measured by serial magnetic resonance imaging. Stroke 42(1): 73-80, 2011
46. Volbers B, Willfarth W, Kuramatsu JB, Struffert T, Dorfler A, Huttner HB, Schwab S, Staykov D: Impact of perihemorrhagic edema on short-term outcome after intracerebral hemorrhage. Neurocrit Care 24(3): 404-412, 2016

47. Yang J, Arima H, Wu G, Heeley E, Delcourt C, Zhou J, Chen G, Wang X, Zhang S, Yu S, Chalmers J, Anderson CS: Prognostic significance of perihematomal edema in acute intracerebral hemorrhage: Pooled analysis from the intensive blood pressure reduction in acute cerebral hemorrhage trial studies. Stroke 46(4): 1009-1013, 2015

48. Yu Y, Zhao W, Zhu CP, Kong ZP, Xu Y, Liu GZ, Gao XG: The clinical effect of deferoxamine mesylate on edema after intracerebral hemorrhage. Plos One 10(4):e0122371, 2015

49. Zheng D, Arima H, Heeley E, Karpin A, Yang J, Chalmers $\mathrm{J}$, Anderson CS: Ambient temperature and volume of perihematomal edema in acute intracerebral haemorrhage: the INTERACT1 study. Int J Stroke 10(1): 25-27, 2015

50. Zheng H, Chen C, Zhang J, Hu Z: Mechanism and therapy of brain edema after intracerebral hemorrhage. Cerebrovasc Dis 42 (3-4): 155-169, 2016

51. Zhou W, Marinescu M, Veltkamp R: Only very early oxygen therapy attenuates posthemorrhagic edema formation and blood-brain barrier disruption in murine intracerebral hemorrhage. Neurocrit Care 22(1): 121-132, 2015

52. Zubkov AY, Mandrekar JN, Claassen DO, Manno EM, Wijdicks EF, Rabinstein AA: Predictors of outcome in warfarin-related intracerebral hemorrhage. Arch Neurol 65(10):1320-1325, 2008 